This item was submitted to Loughborough's Research Repository by the author.

Items in Figshare are protected by copyright, with all rights reserved, unless otherwise indicated.

\title{
Web-based interactive TV services for older users
}

PLEASE CITE THE PUBLISHED VERSION

PUBLISHER

(C) International Society for Gerontechnology

LICENCE

CC BY-NC-ND 4.0

\section{REPOSITORY RECORD}

Mitchell, Val, C.A. Nicolle, Martin Maguire, and H. Boyle. 2019. "Web-based Interactive TV Services for Older Users". figshare. https://hdl.handle.net/2134/2806. 


\title{
Original
}

\section{Web-based interactive TV services for older users}

\author{
V. Mitchell \\ C. Nicolle \\ M. Maguire \\ H. Boyle
}

Ergonomics and Safety Research Institute (ESRI), Loughborough University

Holywell Building, Holywell Park, Loughborough, Leicestershire, LE11

$3 \cup Z$, United Kingdom

E: v.a.mitchell@Iboro.ac.uk

\begin{abstract}
V. Mitchell, C. Nicolle, M. Maguire, H. Boyle. Web-based interactive TV services for older users. Gerontechnology 2007; 6(1):20-32. This article reports a study that explored user requirements for web-based interactive TV (iTV) services from the perspective of older users. Members of a University of the Third Age (U3A) group were recruited for the study in order to explore the potential for web-based iTV to be used as a tool for mediating social communities. Focus groups and user trials were used to explore participants' reactions to the concept of web-based iTV and to identify barriers to use. The study found that the web-based iTV service offered in some contexts several advantages to personal computer use that were valued by study participants. However, significant physical and cognitive barriers to use were identified, such as cost of services, lack of privacy, information overload and learning interface equipment. Recommendations for designing web-based iTV services for older users, generated in response to these concerns, include keeping the user interface simple, avoiding multi-modal keys on the keypad and providing information portals tailored to the interests of older users.
\end{abstract}

\section{Keywords: older users; interactive TV, design guidelines}

Television and the Internet are converging at an ever increasing rate, to create a communication and information medium for the mass market. In Britain some $62 \%$ of households already have access to digital television, many using Freeview digital TV services delivered via a rooftop aerial. In September 2005, the UK Government confirmed that digital switchover will take place between 2008 and 2012 with a plan to steadily shut down all analogue TV signals by $2012^{1}$.

Digital TV offers the opportunity to provide more than just a vast range of TV channels to consumers. Already interactive TV (iTV) services, including Electronic Programme Guides and information services such as $\mathrm{BBCi}$, are widely available. A further extension of the iTV concept is the provision of Internet access alongside digital TV services. Web-based iTV is delivered via a set-top box (STB) connected to the Internet by a telephone line or broadband communication connection. The user is able to surf the World Wide Web (WWW) and send and receive email using a remote control or sometimes a wireless keyboard. As web-based iTV extends access to the Internet to households who have no personal computer $(\mathrm{PC})$, the technology offers the opportunity to considerably widen access to digital information services, including on-line health services and e-government services to user groups currently reluctant or unable to invest in a PC. For example, Kaye ${ }^{2}$ comments: "As the initial hardware costs are lower for a system that is more secure, and much easier to use, than the Internet (all you need is your existing TV, set-top box, telephone point and remote control), [one can] predict Britain's 8.6 million disabled people and their families are more likely to purchase interactive 
television than PCs." However, as noted by Stewart ${ }^{3}$, there is no guarantee that the marriage of television and the Internet will be a happy one. The television is a collectively consumed medium viewed 'passively', from a distance and from the comfort of an armchair. However, websites and email often demand a much higher level of engagement and interaction with the content, usually viewed sitting in an attentive upright position close to a computer screen. Therefore, as well as overcoming the considerable interaction design issues associated with primarily interacting with services using a remote control, there are issues concerning whether the TV is an appropriate mechanism for delivering the Internet to consumers.

For web-based iTV to fulfil its potential as a means for increasing the inclusivity of the WWW, it must be accessible to all, including older users, since a very large percentage of the television audience is made up of disabled and older people, especially during the daytime and non-peak viewing hours ${ }^{4}$. The latter people often have a combination of impairments such as poor hearing/vision, reduced mobility, dexterity and cognitive abilities. Keates and Clarkson ${ }^{5}$ considered the accessibility and usability of digital TV services from the perspective of older users. They found that exclusion can occur because of the complexity of the interaction paradigms related to the concept of digital TV, for instance, the need for 2 remote controls. They also noted that the added functionality of digital television increases the cognitive demands associated with learning and operating the TV. Therefore organisations that are promoting webbased ITV and other iTV services should consider the particular needs of older users in order to identify conceptual barriers to use and opportunities to reduce the complexity of digital TV services.

This paper reports the results of a study that explored user requirements for web-based iTV services from the perspective of older users $^{6}$. The study aimed to: (i) identify user requirements for web-based iTV services relating specifically to the needs of older users; (ii) identify concerns and perceived barriers to web-based iTV being successfully adopted by older users, and (iii) formulate recommendations for successful implementation of web-based iTV in older users' homes.

\section{BACKGROUND}

The study is part of a body of human factors research undertaken in support of the Services Aggregation (SA) Pilot conducted within The Application Home Initiative (TAHI) and sponsored by the UK Department of Trade and Industry (DTI). The SA Pilot was designed to evaluate the commercial and technical case for enabling multiple service providers to deliver easy to use integrated information services to the home using a variety of service delivery platforms. As part of the project a suite of Internet services was developed to be viewed via web-based iTV. These services were evaluated in 15 Leicestershire (UK) homes within what was branded the 'SMART trial'. Central to the SMART trial was an energy and water consumption monitoring service developed by Severn Trent Water, with the support of Leicester City Council. SMART also contained a meal planning tool 'Cheffy', energy saving advice pages and a site specially purposed for TV viewing containing entertainment, travel information and online shops.

SMART utilised a set-top box to deliver digital TV and web-based iTV services enabling both email and web browsing, whilst at the same time being able to view the current TV programme in the top righthand corner ('picture in picture' or PIP).

To make special consideration of the additional service requirements of older users, the service provider wished to also study the user requirements of a specific group of older people. The results of this additional study were fed into the SA Pilot to provide a platform for introducing web- 
based iTV services to a wider population of older users.

Bouwhuis ${ }^{7}$ suggests that gerontechnological research should aim to improve the quality and frequency of social communication for the older user in order to improve integration in society and to support self-fulfilment. This study sought to explore whether web-based iTV has the potential to enhance interaction within an existing group of older users. The University of The Third Age (U3A) was chosen as the user community for this study with members of the U3A in Loughborough recruited to take part. The U3A offers 'Lifelong Learning for Older People'. Third Agers organise their own autonomous learning groups with local U3As now existing all over the world. The U3A does not provide a representative sample of UK older people. Many U3A members are retired professionals and this was represented in the study population which included retired teachers, lecturers and engineers. Although Quigley and Tweed $^{8}$ reported that most of the UK population over 65 had never used computer technology, 15 out of the 20 study participants were regular computer users. However, the service provider was seeking to target existing communities of older people who were likely to be motivated to communicate within a computer mediated social network. The familiarity of the user group with PC-based Internet services allowed the researchers to investigate whether web-based iTV offered particular advantages over accessing similar services using a home PC, leading to a deeper consideration of the particular advantages and disadvantages of using the TV as a delivery platform for Internet services that would not have been achievable if so many of the participants had not previously experienced $\mathrm{PC}$ use.

\section{Use by older computers users}

$\mathrm{Xie}^{9}$ reports that a large number of human factors studies have found age related differences in older adults' learning and use of computers and the Internet that can be attributed to a decline in visual, perceptual, psychomotor and cognitive abilities. However, reduced ability does not necessarily impede fulfilment. According to Nielsen ${ }^{10}$, 'silver surfers' (Internet users over 65) took twice as long to complete online tasks, and had a $53 \%$ success rate compared with the average of $78 \%$ for adults under 65 . However, they were more determined to work their way through websites, even the ones that were poorly designed, and found their Internet usage relatively more satisfying in comparison to younger users.

Hilt and Lipschultz ${ }^{11}$ studied the use of the Internet by older American computer users. They found that in line with the wider population, their study participants varied considerably in their use of the Internet. Email was considered the most important Internet function and was used on a regular basis by most participants to stay in contact with family and friends. When using the Internet to find information, the study participants were more likely to search out information related to their specific interests rather than visiting mass media sites. Hilt and Lipschultz ${ }^{11}$ concluded that there is a need for web portals, perhaps hosted by television and radio stations, through which older users can be provided with access to content that matches their particular interests rather than those of the mass market. Therefore, their research supported the goals of the SMART project service providers who commissioned the U3A study in order to understand the user requirements of a specific older user community for Internet based iTV services.

It is interesting to note that $94 \%$ of people with visual impairment watch television $^{12}$. A high proportion of these people have some useful vision so may be able to access web-TV and other iTV services if all the features are accessible from the onset. Gill and Perera ${ }^{13}$ sent out 400 questionnaires to visually impaired people asking what features they would like on their 
digital televisions. The results showed that the following features would be beneficial: the ability to change text size, the ability to change colour combinations, use of icons, speech input and output, audio description, more time to review any information, and the option to decrease the number of functions available. Gill ${ }^{4}$ states that some older people may take longer to view information displayed on a TV screen as their visual accommodation takes longer to adjust. Some people have to move closer to the screen to view textual information but they are reluctant to do this. They may also have to put their glasses on and off as they focus on the remote control and screen in quick succession, as is often necessary when using interactive functions.

Keates and Clarkson ${ }^{5}$ identified specific causes for concern with regard to interaction with digital television (DTV) delivered via a set-top box. The majority of their sample age ranged from 62-85 years old. They found that for this population there was a high cognitive, visual and dexterity demand on the participants associated with using DTV. They recommended to manufacturers that cognitive demand should be kept to a minimum and the interaction with the set-top boxes should be as transparent as possible. These improvements to the provision of DTV would be beneficial to the population as a whole and therefore would facilitate the transition from analogue to digital TV. Other impairments can be accommodated by ensuring that messages can be perceived in both audio and visual modes. Remote controls should have clear visual markings, large and wellseparated buttons, with distinct shapes to help distinguish functions, clear text and symbols with good contrast ${ }^{13}$.

Sit and Fisk ${ }^{14}$ noted that one of the most dramatic changes associated with ageing is the decline in the ability to do two or more things at once. For example, older users may find it difficult to position the keyboard on their lap in order to obtain a signal from the set-top box while typ- ing and looking at the television all at the same time.

\section{Web-TV versus $P C$ use}

The context of use for web-based ITV is very different from that usually associated with using a PC. Chorianopoulos ${ }^{15}$ notes that usability design principles developed for desk top PCs do not translate to the design of iTV services. He reasons that this is largely due to users adopting an entertainment-orientated approach to interacting with TV services that is very different to the task-orientated approach adopted by users of PC-based applications. However, differences in the characteristics of the TV and PC viewing platforms and available interaction modes equally demand a fresh approach to developing user interfaces to be viewed over the TV platform. The main differences are as follows ${ }^{16}$ :

(i) Although the TV screen is usually larger than a computer monitor, the viewing distance is also greater and the resolution poorer (although this will change with the take up of high definition TV). Therefore only about 20 lines of text can be easily read from a TV screen viewed at a normal living room distance.

(ii) The TV does not support direct manipulation of content as no freely moveable cursor is available for moving or editing content on screen.

(iii) Use of TV applications, like mobile phone applications, is based upon arrow buttons, selection and number buttons. Scrollable content is therefore not recommended. Separate pages of content should instead be displayed on the TV.

(iv) On a PC user interface it is necessary to highlight which components on screen can be selected or edited. Within TV user interfaces, in addition to these issues, the emphasis is upon explaining which buttons on the remote control can be used to interact with the service and how they can be used to navigate around the available content.

(v) Although a wireless keyboard is often provided with web-based iTV services, 
the designer cannot rely on its availability and therefore must ensure that all content can be navigated and manipulated using a handheld remote control.

\section{iTV guidelines}

Darnell ${ }^{17}$ describes how many Americans buy web-based iTV because they are uncomfortable with computers, often because they have no experience of computing. The challenge for web-based iTV design is, therefore, to ensure that services are easy to learn and use. iTV usability guidelines have been developed to take into account the specific usability challenges arising from this platform. These guidelines actively promote Inclusive Design adhering to the principle that good design for disabled and older people is frequently good design for everyone. In November 2003, The European Committee for Electrotechnical Standardization formulated the 'Standardisation Requirements for Access to Digital TV and Interactive Services by Disabled People' ${ }^{18}$. Guidelines included in the report are on the equipment, access, services, Electronic Programme Guides and navigational menus.

The Tiresias website ${ }^{19}$ also provides guidelines on iTV for the visually impaired. The guidelines cover topics such as iTV applications, on-screen display, remote control, customisation, and websites. However, even if the user interface to iTV is designed with older users in mind, it is still necessary to ensure that the services promulgated through iTV are useful and desirable. Stewart ${ }^{3}$ notes that one of the greatest challenges facing the providers of iTV services is the increasing availability of PCs within the home environment. He concludes that the most successful iTV applications will be those that take advantage of the convergence of TV and computing platforms and offer value to the user that exploits the TV-centric context of use. As the user population of this study shows, home PCs are also becoming commonplace amongst older users, at least from certain socio-eco- nomic sectors. This domestication of the $\mathrm{PC}$ is likely to continue as computer use in schools and the workspace becomes commonplace and the cost of PCs continues to decline. Therefore, does it make sense in the long run to develop the TV as an access point to the Internet if $\mathrm{PC}$ access in the home is to become the norm? The focus of this study, therefore, was upon eliciting user requirements for web-based TV services. In particular, what web-based interactive TV services would be particularly welcomed by the older population and what value, if any, is added to these services by providing access via the TV? Unless web-TV offers particular advantages to users above those provided by having access to the Internet via a PC, then the future of web-TV will remain uncertain.

\section{Methodology}

Data collection involved qualitative research methods using focus groups, user trials and interviews (Tables 1 and 2).

\section{Focus groups}

In the first phase of the data collection, focus groups were used as they provided a suitable technique for initially assessing user needs and feelings within a relaxed atmosphere. In the focus groups, individuals did not get the chance to explore the web-based ITV system on their own; instead, the moderator provided a product demonstration as the basis for discussion. The aims of the focus group were: (i) to demonstrate and introduce web-based iTV to the group; (ii) to obtain their initial views on web-based iTV; (iii) to investigate any concerns and barriers they could foresee; (iv) to identify facilities accessed through web-based iTV that would be of interest to the group; and (v) to explore the possibility of the U3A using web-based iTV as a platform for service delivery.

The first session took place at the home of a married couple from the U3A in order to provide a realistic environment within which to introduce and explore the con- 
Table 1. Description of the focus group sample; $n=20$

\begin{tabular}{l|c}
\hline \multicolumn{2}{c}{ Gender } \\
\hline Male & 8 \\
Female & 12 \\
\hline \multicolumn{3}{c}{ Age [yrs] } \\
\hline $80-89$ & 2 \\
$70-79$ & 16 \\
$60-69$ & 2 \\
\hline \multicolumn{3}{c}{ Computer usage } \\
\hline Users & 15 \\
Non-users & 5 \\
\hline
\end{tabular}

cept of web-based iTV (Figure 1). SMART was installed in their home, including the energy and water usage monitoring system. The other two focus groups were held at ESRI as they contained members of the U3A not known to the first couple, therefore avoiding any awkwardness that may have occurred because other participants felt they were intruding into someone else's home. However, a similar informal atmosphere was created within the ESRI meetings.
Table 2. Description of the user trials sample; $n=8$

\begin{tabular}{|c|c|}
\hline \multicolumn{2}{|c|}{ Gender } \\
\hline Male & 4 \\
\hline Female & 4 \\
\hline \multicolumn{2}{|c|}{ Age [yrs] } \\
\hline 80-89 & 2 \\
\hline $70-79$ & 6 \\
\hline $60-69$ & 0 \\
\hline \multicolumn{2}{|c|}{ Computer usage } \\
\hline Users & 4 \\
\hline Non-users & 4 \\
\hline
\end{tabular}

At the beginning of each focus group, the web-based iTV and the SMART services in particular were demonstrated. The users were then asked to discuss their initial requirements, concerns and issues related to the service. A concept board was introduced to generate new concepts and ideas about web-based iTV. The participants were encouraged to select pictures from a range provided and then to choose an image that would represent facilities they would like to see provided. Using a word

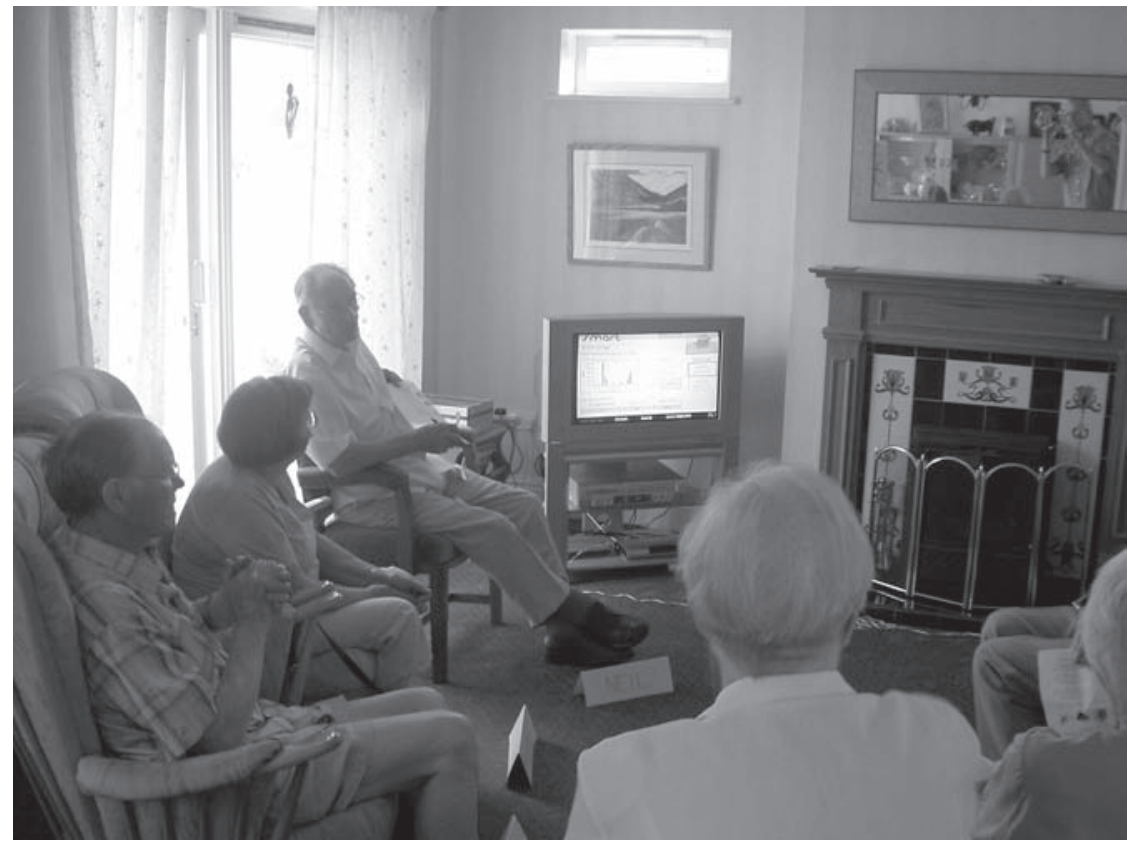


map, participants were also asked to provide a word or sentence on their concerns or issues, and these were placed on a flip chart to prompt further discussion. Finally, the users were asked to complete a questionnaire, and the researcher provided any assistance that was needed.

\section{User trials}

To assess whether users experienced any usability problems when operating the web-based iTV system and to explore user requirements in more detail, one to one user trials were conducted. After piloting of the method, eight participants from the initial focus group stage took part in these trials. The trials were audio-taped and later transcribed in preparation for analysis. On arrival at the home used in the first focus group, participants were given a choice of where to sit, i.e., where they would usually sit when watching their own TV. The choice of a hard back chair $(1.70 \mathrm{~m}$ distance from TV) and an armchair (approximately $2 \mathrm{~m}$ viewing distance) were offered. Only the participant and researcher were present during the trial. The aims of the user trials were: (i) to allow the participants to experience actual use of web-based iTV; (ii) to explore the findings from the focus group in more depth in order to highlight key user requirements including barriers to use; (iii) to identify if there were any differences between computer/non-computer users relating to their requirements for web-based iTV; (iv) to assess the usability of the equipment and services on an individual basis; and (v) to identify participants' impairments in more detail to ascertain if these were causing any particular problems when interacting with web-based iTV.

The user trial consisted of four stages: (i) gathering of background information; (ii) introduction to the trial tasks; (iii) completion of tasks presented in scenario form, and (iv) post-trial interview in the form of a questionnaire.

Users were asked to complete a set of pre-determined tasks, using common usage scenarios, for example, viewing and interpreting energy and water saving information, and planning a meal with specific ingredients using the Cheffy meal planning tool. They were also asked to perform a Google search and send an email using the digital TV email service. The researcher observed these activities and recorded the time to task completion or failure, the number of errors and the level of assistance that they required. Although these measures allowed the usability of the system to be assessed, usability was not stringently tested as the aim of the study was primarily to gather user requirements. The use of web-based iTV in living room surroundings allowed the investigator to observe the users in a natural setting and made the experience more realistic for the participants.

\section{Data ANAlysis}

Both the focus groups and user trials were transcribed and imported into a qualitative data management tool, $\mathrm{Nvivo}^{20}$. The data were summarised, coded (using axial coding) and broken down into categories so that any themes that arose of relevance to the project were captured. Memos, quotes, and references were linked to each code. Nvivo does not analyse the data as a statistical package might; it simply provides an environment to store and explore the data and ideas ${ }^{21}$. Data analysis occurs through the process of coding, data reduction is achieved through formulating the codes into trees, and finally data is displayed to allow themes to be reviewed and assimilated.

\section{Results}

\section{PC users vs. non-users}

Fifteen out of the 20 participants were computer users, and therefore, these results are not statistically significant, but are nevertheless interesting. The computer users taking part in the study recorded the following uses for their PCs: research, games, Internet, email, Word, Excel, family 
history, photo storage, letters, banking, and making bookings. The time scales of computer usage ranged from ten participants using it daily, one using it weekly and one using it fortnightly. The remaining three did not answer. During the focus groups, the existing computer users were asked after the demonstration of web-based iTV, whether they preferred the web-based iTV service or PC-based access to the Internet. 3 preferred the web-based iTV, 7 PC-based access, 4 preferred a combination of both, and 1 provided no response.

The 7 PC users who preferred PC access could not see any advantages to having access to the Internet over the TV. However, there was some indication from the discussions that a number of participants struggled to see the two systems as being possibly complementary - instead they were only willing to consider the option of having one or the other solution and not both systems together. A number of the participants preferring the PC solution perceived that the only advantage to having the set-top box related to the provision of the extra Freeview digital channels.

One of the participants that preferred a combination of TV and PC-based solutions highlighted that iTV was more convenient for emails as it took too long to log on to the PC. Another stated that the iTV system was more convenient for emails as you did not have to go into another room to check your mail. This suggests that the users would like to be able to casually check for emails outside of periods when the PC is switched on. Being able to check for mail between TV programmes was therefore an advantage offered by the web-based iTV system that is not easily met by the PCbased alternative. The one computer user who had the SMART service actually installed in her home found that the dual operation of the PC and web-based iTV system had made it difficult for her to manage her emails. She found that she was unable to open up emails on the TV that had been previously opened on the PC. Whereas this problem was solved with assistance by re-configuring the PC-based email service so that emails remained on the message server rather than being 'pulled' from the server to the PC, the problem showed how easily the complexity of a service can be increased by introducing new technology. Therefore, just as digital TV was found by Keates and Clarkson ${ }^{5}$ to significantly increase the cognitive loading for older users associated with watching TV, web-based iTV may further increase this loading unless its implementation alongside existing computer systems is carefully managed.

The web-based iTV service was also viewed by one participant as a better medium than the PC for sharing information. Whereas the computer is one to one, the TV is better to use when wanting to see about a holiday or shopping and therefore there is a possibility to discuss with others and make suggestions. This may be a particular issue for older users who may be uncomfortable crouching or leaning awkwardly to see a PC screen when there is typically only one chair in front of the screen.

Concerns raised about web-based iTV from the existing computer users often related to wanting the system to offer the same functionality as a PC. For example, users asked whether they would be able to type documents, print, or attach documents to emails. This again shows confusion over the purpose of the system. Rather than viewing web-based iTV as an extension to digital TV services, these users appeared to be viewing the system as a PC that used the TV screen as a monitor and replaced the keyboard and mouse with the remote control and wireless keyboard. The result from this perspective was a poorly specified computer that performed badly in comparison with a desktop PC. As well as raising expectations, this sort of confusion can lead to usability problems, as users apply an inappropriate interaction paradigm when attempting to use services. 
Designers of web-based iTV services must, therefore, be careful to develop content and user interfaces that build on user interface paradigms being established through the application of iTV usability guidelines, such as those developed within CENELEC ${ }^{18}$ and applied to good effect within $\mathrm{BBCi}^{22}$.

With regard to the five non-computer users within the focus groups, four of them preferred using the iTV as opposed to the computer and one thought they would prefer to use a computer. Overall the noncomputer users felt they would be gaining if they had web-based iTV as they did not have a computer. Another participant was relieved that there was no need for previous computing experience when using the service, although this participant preferred the size of the font on the TV compared to the computer. This comment demonstrates a lack of knowledge of the adjustments that can be made on a PC to increase the size of the font, and adjust other accessibility options.

\section{Service requirements}

During the focus groups most of the participants were not interested in the concept of a U3A service developed specifically for web-based iTV. However, those who took part in the user trials were able to become more familiar with the web-based iTV concept and were then more forthcoming with $\mathrm{U} 3 \mathrm{~A}$ related requirements. A possible explanation is that the study introduced a number of new technology concepts and there was no time within the focus groups to properly assimilate these concepts. The opportunity to try the service for themselves therefore gave the participants the chance to explore more fully its nature and consider their requirements at a more measured pace. Eisma et al. ${ }^{23}$ suggest that older people use technology less than younger people because they are more likely to fear it. This may also have been a factor affecting the outcomes of the focus groups.

When discussing their requirements in re- lation to U3A activities, participants were interested in being able to access information about the courses on offer in their area. Cost of service use was, however, an overriding issue for participants supporting previous literature ${ }^{24}$. Ekberg and Roe $^{25}$ have stipulated in their guidelines for uptake of technology with older users that products need to be affordable in order to be accessible to them. The provision of email facilities for contacting other members was a popular option even with the non-computer users. 'Access for all' to the U3A's online information services was viewed as a positive concept, in line with the U3A philosophy. iTV was generally viewed as a good mechanism for providing this access that could easily be made available to all members, not just those with computers.

\section{Concerns}

The study participants expressed many concerns about the concept of web-iTV both within the focus groups and user trials. The data analysis led to these concerns being grouped into nine themes as follows:

(i) Information overload. This concern mainly related to users having to assimilate many new concepts when learning about and trying web-based iTV for the first time. However, concerns were also expressed about using the TV which was meant for relaxation as a tool for looking up information. That using web-based iTV was perceived as work rather than relaxation may have been accentuated as the users were using the system for the first time which required considerable concentration and effort for many of the older users in the trial. (ii) Privacy. If other family members were present when the user was reading and writing emails.

(iii) Confusion. Web-based iTV offers more functionality and thus requires more cognitive effort to learn and operate than ordinary TV.

(iv) Equipment. Usability issues were raised particularly relating to use of the re- 
mote control. Some users also found the keyboard uncomfortable to use when resting on the lap as little wrist support was provided.

(v) Printing. There was no facility for printing within the web-based iTV system.

(vi) Monopolising the TV, when others may wish to watch it.

(vii) Cost. Concerns were expressed about the cost of the set-top box, broadband connection, and provision of services.

(viii) Impairments. Some participants had difficulties manipulating the remote control due to arthritis and others had difficulty scanning the TV and reading the keyboard when wearing varifocals or separate glasses for reading and distance.

(ix) Need for simple language. Common key labels such as 'Home' and 'Back' used within the services and already familiar to users of mobile phones were still confusing for many of the older users. Different arrows for navigation within web services, for programme selection and for TV settings also caused confusion.

Many of these concerns are unlikely to be unique to the older user population. However, in line with the findings of Keates and Clarkson ${ }^{5}$ relating to the use of DTV services, this study showed that the trial web-based iTV system placed high cognitive, visual and dexterity demands upon older users. The user trials showed the study participants struggling to interact with the technology even though the user interfaces were well designed in line with existing iTV usability guidelines. The problems experienced related mostly to the need to assimilate so many new concepts at once in order to make sense of and learn to operate the system. These new concepts included: (i) using a wireless keyboard positioned on the lap to navigate and select screen based content, (ii) having to look down at the keyboard and then back up to the screen to see the effect of each key press, (iii) the novelty of web-based information being displayed on the TV screen, (iv) understanding the difference between existing digital services such as BBCi and the web-based content introduced in the trial, including questions about where the Internet content was coming from (such as the aerial), (v) understanding the concept of wireless broadband (Why was no wired link needed to the phone line?), (vi) the novelty of digital TV, including having to make sense of how extra channels were now available through the existing TV aerial, and (vii) the remote control included with the set-top box provided in the trial was poorly designed and it was easy to accidentally hit the wrong buttons which made it difficult to build up a consistent mental model of the navigation structure.

Although the majority of the participants felt that the layout of the keyboard was in keeping with the traditional computer keyboard (apart from the shortcut keys and programme/volume keys), the use of it on their lap seemed to be problematic. Although most of the participants stated that they had no problem using the keyboard on their lap, many of them chose to predominately use the remote control stating it was more familiar to them. The participant that had the iTV for a number of weeks placed the keyboard on a tray with a bean bag base which allowed for more stability and comfort. If a service provider wants to target an older user community group such as the U3A they will need to give careful thought to the keyboard design. Considering that older people can have a number of musculoskeletal conditions related to age, there are a number of problems that could arise if they are in a sustained position for any length of time, for instance balancing the keyboard on their lap with no wrist supports, whilst reading on screen text from an armchair. TV viewing is in the mode of relaxation, i.e. 'lean back technology' whereas computer viewing is more intense ('lean forward technology' $)^{26}$. Technology used in such home situations needs to consider alternative hardware solutions to accommodate this 'lean back' posture, for instance 
by providing a keyboard base conforming to the contours of the user's lap.

\section{Discussion}

This study has identified a range of older user requirements relating to the use of web-based iTV. Despite the provision of usability guidelines for the design of user

The common reaction of the study group to making mistakes when trying out the system was that it was their fault, rather than the result of poorly designed technology. The computer users in the sample exhibited a similar attitude towards their computers. For example, one participant commented that "when things go wrong you think it is your fault all the time". There was, however, evidence from the comments of the participants that web-based iTV could be less intimidating than the computer, as the TV was generally viewed as a friendly and familiar piece of equipment. However, for this to occur many of the conceptual and physical barriers to use identified within this study need to be minimised within the design of future web-based iTV systems and services.

\section{ReCOMmendATIONS}

The following nine recommendations are made to reduce these barriers to use:

(i) Appropriate hardware solutions. Remote controls used to navigate web-based content on the TV should help the user clearly distinguish between keys used to navigate web-based content and those used to control the choice of programmes. The use of multimodal keys should be avoided wherever possible and the design should prevent the user from inadvertently switching between TV and Internet modes. Wireless keyboards provided with web-based iTV systems should be designed specifically to sit comfortably in the lap for long periods of time perhaps through the use of a gel or sponge base. Good support for the wrists should be provided given the likely occurrence of wrist problems amongst older users. Keyboards should also be aesthetically designed to blend into the domestic context of use. The keyboard used in this study was black and more suited to an office than the home environment.

(ii) Easy to use tailored services. Although the services provided largely adhered to the available usability guidelines for the design of iTV services, the study users still found it difficult to navigate and select content when completing the study tasks. This suggests that older users may benefit from the provision of bespoke service portals that offer access to services of specific interest to older users designed to further simplify navigation. This supports the findings of Hilt and Lipschultz ${ }^{10}$ who recommend that older users are shielded from the complexity of multi-channel digital TV by the provision of portals providing easy access to channels of particular interest.

(iii) Clear user interface paradigm. This would make it clear to users that webbased ITV is an extension to TV usage not a poorly specified alternative to a deskbased PC. This may require the use of a 'walled garden' that prevents users accessing Internet content that has not been specifically repurposed for viewing over the TV. 
(iv) Support communities of users. The study participants valued the potential inclusivity of web-based iTV and welcomed the opportunity to provide on-line access to messaging and information services to all U3A members. Community-based sites can be designed to specifically address the needs of older users as discussed above. Support networks both online and within the local community can be used to break down barriers to use and encourage use amongst even the most wary users.

(v) Exploit the TV platform. The study participants were able to identify contexts of use where web-based iTV may offer advantages over the PC. The TV was identified as potentially a more suitable platform for sharing and discussing information with others, for example when booking a holiday or displaying photos. Service providers should look for other opportunities to exploit the availability of a large shared screen within a living space. For example, in the U3A context content could be developed to support the activities of homebased study groups. Photo sharing and 'Blogging' services could also be adapted to the needs of U3A members by providing a simple way of gathering and collectively sharing photos and experiences from events and outings.

(vi) Simple email access. Many study participants, including those who had never used email before, liked the idea of being able to quickly check for messages during advertisement breaks or between programmes when watching TV. Services could provide a fixed shortcut on the remote control to email as suggested by study participants. However, the opportunity to password email access should still be provided to reflect the concerns of users who were worried about others reading their emails. This would not stop others in the room reading emails on the shared screen but would at least prevent unauthorised access.

(vii) Breakdown of costs. Many participants were worried about hidden costs of broadband, equipment, services, support, etc.

(viii) Free help-line within service packages targeted at older users to encourage users to seek help when needed.

(ix) Integrated equipment. Much of the increased cognitive loading experienced by the study participants resulted from the need to use multiple boxes and controls to provide the service. In future, both digital TV and web-based iTV may become integrated into the TV set. This will eventually greatly reduce the complexity of service provision.

\section{Conclusion}

The results of this study support the warning of Stewart ${ }^{3}$ who predicted that the marriage between the Internet and TV would not necessarily be an easy one. For older users the barriers to use associated with the use of existing web-based iTV services are particularly high. This study has explored the concerns and perceived barriers to use from the perspective of an existing community of older users. This has led to the development of design recommendations that may help future service developers alleviate some of these problems and enable web-based iTV to become an accepted and valued way for accessing Internet-based services from the comfort of the living room.

\section{Acknowledgements}

The authors wish to give a special thanks to members of the Charnwood and Loughborough branches of the U3A for their participation and genuine interest in this research. Thanks also go to HomeRider Systems; Severn Trent Water and the DTI TAHI SA pilot for supporting this research.

\section{References}

1. Lowery Miller K. The Airwaves Go Digital. Newsweek 2005; June 13:59-63

2. Kaye J. Why Interactive Will Mean Active. 2000; www.guardian.co.uk/Archive/Article/0,4273,4051721,00.htm; Retrieved February 2006

3. Stewart J. Interactive Television at Home: Television Meets the Internet - An Inno- 
vative Environment for Interactive TV. In: Toscan C, Jensen J, editors. Television of the Future - or: The Future of Television? Aalborg: Aalborg University Press; 1999

4. Gill J. Inclusive Design of Interactive Television. 2004; www.tiresias.org/reports/dtg.htm; Retrieved February 2006

5. Keates S, Clarkson J. Assessing the Accessibility of Digital Television Set-Top Boxes. In: Keates S, Clarkson J, Langdon $\mathrm{P}$, Robinson P, editors. Designing a More Inclusive World. London: Springer; 2004; pp183-192

6. Boyle $\mathrm{H}$. User requirements study on interactive television with older users, MSc thesis in Ergonomics; Department of Human Sciences, Loughborough University, September 2005

7. Bouwhuis D. Design for Person-Environment Interaction in Older Age: A Gerontechnological Perspective. Gerontechnology 2003;3:232-246

8. Quigley G, Tweed C. Added-Value Services from the Installation of Assistive Technologies for the Elderly. 1999; www.qub.ac.uk/arc/ research/projects/papers/AddedValue. pdf; Retrieved February 2006

9. Xie B. Older adults, computers, and the Internet: Future directions. Gerontechnology 2003;4:289-305

10. Nielsen J. Usability for Senior Citizens. Alertbox 2002; www.useit.com/alertbox/ 20020428.html; Retrieved February 2006

11. Hilt M, Lipschultz J. Elderly Americans and the Internet: email, TV news, Information and Entertainment Websites. Educational Gerontology 2004;1:57-72

12. Bruce I, McKennel A, Walker E. Blind and Partially Sighted Adults in Britain: The RNIB Survey. London: HMSO; 1991

13. Gill J, Perera S. Accessible Universal Design of Interactive Digital Television. 2004; www.tiresias.org/reports/brighton. htm; Retrieved February 2006

14. Sit R, Fisk A. Age Related Performance in a Multiple-Task Environment. Human Factors 1999;41:26-34

15. Chorianopoulos K. The Digital Set-Top Box as a Virtual Channel Provider. Doctoral Consortium CHI 2003, 5-10 April, Ft. Lauderdale, Florida, USA. New York: ACM Press; 2003
16. Rinnetmaki M, Heikkinen M. A Guide for Digital TV Service Producers. Helsinki: ArviD; 2004

17. Darnell E. Microsoft Web-TV Brief. Interactions 2000: Bi-monthly publication of the Association for Computing, New York: ACM Press; 2000

18. CENELEC. Standardisation Requirements for Access to Digital TV and Interactive Services by Disabled People. 2003; www.cenelec.org/Cenelec/ CENELEC+in+action/Horizontal+areas/ ICT/Digital+TV.htm; Retrieved February 2006

19. Tiresias. 2006; www.tiresias.org/guidelines/television.htm; Retrieved February 2006

20. Nvivo; www.qsrinternational.com/products/productoverview/product_overview. htm; Retrieved 19 September 2006

21. Hignett S. Qualitative Methodology. In: Wilson J, Corlett N, editors. Evaluation of Human Work. $3^{\text {rd }}$ edition. London: Taylor \& Francis; 2004; pp 113-128

22. BBCi; www.bbc.co.uk/commissioning/newmedia/BBCiguidelines2.pdf; Retrieved 19 September 2006

23. Eisma R, Dickinson A, Goodman J, Syme A, Tiwari L, Newell AF. Early User Involvement in the Development of Information Technology-Related Products for Older People. Universal Access in the Information Society 2004;2:131-140

24. Carey J. Interactive Television Trials and Marketplace Experiences. Multimedia Tools and Applications 1997;5:207-216

25. Ekberg J, Roe P. Guidelines for Telecommunications. In: Nicolle C, Abascal J, editors. Inclusive Design Guidelines for $\mathrm{HCl}$. London:Taylor \& Francis; 2001; pp 167-177

26. Ling R, Meinich F, Nilsen S, Thrane K, Gripsrud M, Johansen L, Andersson K, Pedersen L, Telenor HB. Project Deliverable D19: Evaluation of pilot servicesFinal report. Oslo: Corporate project report; 2001 